\title{
The detection of left ventricular scar by delayed enhancement-CMR in non-ischemic cardiomyopathy is a stronger predictor of cardiovascular events than left ventricular ejection fraction
}

\author{
Carlos M Orrego ${ }^{1,2^{*}}$, Andrea M Cordero-Reyes ${ }^{1}$, Mohamad G Ghosn ${ }^{3}$, Jerry D Estep ${ }^{1,2}$, Guillermo Torre-Amione ${ }^{1,2}$, \\ Sven Zuehlsdorff', Gary R McNeal ${ }^{4}$, Dipan J Shah ${ }^{1,2}$ \\ From 16th Annual SCMR Scientific Sessions \\ San Francisco, CA, USA. 31 January - 3 February 2013
}

\section{Background}

Left ventricular ejection fraction (LVEF) is a strong predictor of subsequent cardiovascular events in patients with ischemic and non-ischemic cardiomyopathy. CMR is an excellent technique for assessment of LVEF as well as for the detection of myocardial scar. We sought to evaluate if the presence of myocardial scarring in nonischemic cardiomyopathy could be an important predictor of cardiovascular events.

\section{Methods}

Inclusion criteria were absence of coronary artery disease, a diagnosis of cardiomyopathy and an LVEF $\leq 45 \%$. Patients with a diagnosis of infiltrative disorders, hypertrophic cardiomyopathy, or tachycardia-induced cardiomyopathy were excluded. A total of 132 patients (with greater than 12 months follow up) were analyzed. Imaging was performed on a 1.5 Tesla Avanto, or 3.0 Tesla Verio MRI scanner (Siemens Medical Solutions). Cine images were performed using a steady state free precession pulse sequence. Delayed enhancement (DE) CMR was performed 10 minutes after administration of 0.15 $\mathrm{mmol} / \mathrm{kg}$ Gadopentetate Dimeglumine (Bayer HealthCare) with typical in-plane resolution $18 \times 2.0 \mathrm{~mm}$, slice thickness 6-7 mm. LV and RV volumes and EF were analyzed by manual planimetry of endocardial contours during end-diastole and end-systole. DE-CMR images were analyzed to identify hyperenhanced myocardium (> 2 SD of remote signal intensity). The primary outcome was a combination of hospitalization for heart failure, LV assist device (LVAD) implantation, cardiac transplant, or death. Adjusted Kaplan-Meier curves were constructed for groups with and without scar by CMR with $\mathrm{p}<0.05$ considered significant. Multivariate logistic regression analysis was performed.

\section{Results}

Patient's demographics are shown in table. All baseline demographic data were similar between patients with and without scar by CMR. The adjusted event-free survival rate was significantly lower for patients with scar compared to patients without scar by CMR at 2-years $(\mathrm{p}=0.03)$ (graph). Mean scar burden was $3 \pm 8 \%$ of LV. On multivariable analysis, the presence of scar was an independent predictor of events, HR 2.5(CI: 0.98-6.38, $\mathrm{p}=0.04)$, but LVEF was not.

\section{Conclusions}

In non-ischemic cardiomyopathy the presence of LV scar measured by DE-CMR is a stronger predictor of cardiovascular events than LVEF.

\section{Funding}

Research grant from Siemens.

${ }^{1}$ Cardiology, The Methodist Hospital, Houston, TX, USA

Full list of author information is available at the end of the article

(C) 2013 Orrego et al; licensee BioMed Central Ltd. This is an Open Access article distributed under the terms of the Creative Commons Attribution License (http://creativecommons.org/licenses/by/2.0), which permits unrestricted use, distribution, and reproduction in any medium, provided the original work is properly cited. 
Table 1 Patient Characteristics

\begin{tabular}{|c|c|c|c|c|}
\hline & All & Without Scar & With scar & $p$ value \\
\hline Patients (n) & 132 & 65 & 67 & \\
\hline \multicolumn{5}{|l|}{ Clinical characteristics } \\
\hline Age (years) & $51 \pm 12$ & $51 \pm 16$ & $50 \pm 12$ & 0.7 \\
\hline BMI (kg/m2) & $31 \pm 9$ & $30 \pm 8$ & $32 \pm 9$ & 0.6 \\
\hline Male gender (\%) & $75(57 \%)$ & $32(49 \%)$ & $43(64 \%)$ & 0.06 \\
\hline \multicolumn{5}{|l|}{ Race } \\
\hline Caucasian (\%) & $70(53 \%)$ & $36(56 \%)$ & $34(51 \%)$ & 0.8 \\
\hline Black (\%) & $35(27 \%)$ & $17(26 \%)$ & $18(27 \%)$ & 0.9 \\
\hline Hispanic (\%) & $17(12 \%)$ & $10(15 \%)$ & $7(10 \%)$ & 0.8 \\
\hline Other (\%) & $10(8 \%)$ & $2(3 \%)$ & $8(12 \%)$ & 0.08 \\
\hline DM (\%) & $26(20 \%)$ & $15(23 \%)$ & $16(24 \%)$ & 0.9 \\
\hline HTN (\%) & 45(34\%) & $26(40 \%)$ & $29(43 \%)$ & 0.5 \\
\hline \multicolumn{5}{|l|}{ CMR findings } \\
\hline LVEF(\%) & $31 \pm 11 \%$ & $33 \pm 10$ & $30 \pm 10$ & 0.09 \\
\hline Scar burden & $3 \pm 5$ & N/A & $6 \pm 6$ & N/A \\
\hline
\end{tabular}

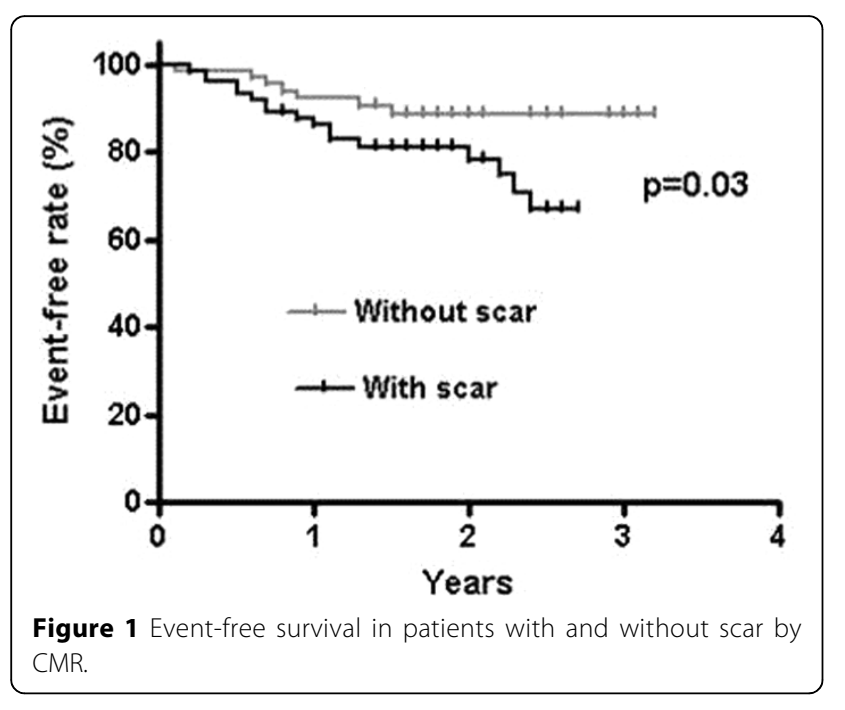

Author details

${ }^{1}$ Cardiology, The Methodist Hospital, Houston, TX, USA. ${ }^{2}$ Cardiology, Weill Cornell Medical College, Houston, TX, USA. ${ }^{3}$ Baylor College of Medicine, Houston, TX, USA. ${ }^{4}$ Siemens, Houston, TX, USA.

Published: 30 January 2013

\section{doi:10.1186/1532-429X-15-S1-095}

Cite this article as: Orrego et al: The detection of left ventricular scar by delayed enhancement-CMR in non-ischemic cardiomyopathy is a stronger predictor of cardiovascular events than left ventricular ejection fraction. Journal of Cardiovascular Magnetic Resonance 2013 15(Suppl 1): 095.
Submit your next manuscript to BioMed Central and take full advantage of:

- Convenient online submission

- Thorough peer review

- No space constraints or color figure charges

- Immediate publication on acceptance

- Inclusion in PubMed, CAS, Scopus and Google Scholar

- Research which is freely available for redistribution

Submit your manuscript at www.biomedcentral.com/submit
C Biomed Central 